\title{
New Methods and Models of Group Decision and Negotiation Presented in Recife
}

\author{
Adiel T. de Almeida • Danielle C. Morais
}

Published online: 6 November 2013

(C) Springer Science+Business Media Dordrecht 2013

\section{Group Decision and Negotiation in Brazil}

We are glad to be offered the possibility of editing this special issue on selected papers presented at the Group Decision and Negotiation (GDN) conference in Recife, in which we acted respectively as Chair of the Program Committee and the Organizing Committee. Since 2000, in Glasgow, GDN meetings traditionally bring together researchers and practitioners from Africa, the Americas, Asia, Europe, and Oceania.

GDN 2012 was the 12th Annual Meeting and the first time the conference was organized in Latin America, namely in Recife, Brazil, by the Universidade Federal de Pernambuco. This conference in Recife was a great opportunity to show the variety of methodological research studies and application models on group decision and negotiation developed in Brazil, which deal with different types of problems, such as social security, public policy, water resources management, information systems, project portfolio selection, supplier selection and participatory budget.

From the perspective of Latin America there are studies including a diversity of practical application and methodological developments, which have given insights on how to deal with a diversity of cultural issues (Almeida and Costa 2012). A growth in the demand for GDN models in order to overcome a variety of problems has been noticeable in daily business life. In Brazil, there is a huge opportunity for developments of GDN models and applications. Although, an increasing number of studies related to GDN models in Brazil have been developed in recent years, there is still a large opportunity to produce research related to the relevant literature, similar to the situation

\footnotetext{
A. T. de Almeida . D. C. Morais $(\varangle)$

Universidade Federal de Pernambuco-UFPE, Recife, Brazil

e-mail: daniellemorais@yahoo.com.br
}

A. T. de Almeida

e-mail: almeidaatd@gmail.com 
related to GDN models in Latin America (Almeida and Costa 2012). This imbalance between the demand from society and the relevant research published to date shows clearly an opportunity for new developments and applications in the field related to this environment.

There are many studies conducted on GDN in Brazil which emphasize applications, including new methodological issues, such as:

- Water management (Silva et al. 2010; Morais and Almeida 2006);

- Supplier selection (Alencar and Almeida 2010; Alencar et al. 2010; Baccarin et al. 2011);

- Participatory budget (Santos 1998; Alfaro et al. 2010);

- Veto procedure for additive group aggregation models (Daher and Almeida 2012);

- Fuzzy Approach for expert group aggregation models (Ekel et al. 2009; Parreiras et al. 2010, 2012; Krohling and Campanharo 2011).

- Voting procedures (Morais and Almeida 2010, 2012);

It has been noticed that there is a clear opportunity for developments of GDN models and applications in several situations in order to meet an increasing demand for these kinds of models.

\section{New Methods and Models Presented in Recife}

Eleven papers have been selected from those presented at the GDN 2012 conference. This special issue includes nine of those papers, and two other papers are in next regular issue following this special issue. The authors of these papers are from Australia, Brazil, Canada, China, Italy, Japan, Poland, Saudi Arabia, Sweden, and United Kingdom.

This selection of papers reflects the diversity of research studies presented at the conference, and includes theoretical procedures being developed for GDN and practical experiments to explore and validate specific settings.

The first three papers of this issue are related to Games and Negotiations, and analyze different aspects of these. The first is about conflict resolution and its contents formed the basis of the keynote address by K. W. Hipel at GDN 2012. In this paper Keith W. Hipel, D. Marc Kilgour and Rami A. Kinsara analyzed three historical conflicts over water that occurred along the Euphrates River in 1975, 1990 and 1998. They noted that the unilateral development of water resources without the coordination and cooperation of other countries sharing the same water resource may create conflict. Then they modeled the conflicts using the Graph Model for Conflict Resolution, thereby providing an important real-world application of a graphical model, and showing the importance of Third Party intervention in resolving conflicts. Due to this study it is possible to observe the causes and resolutions of these disputes and to learn how to effectively manage similar situations in the future.

The second paper, written by Filipe C Souza and Leandro C Rego, used Game Theory to study experimentally $2 \times 2$ matrix games from three aspects: whether the players play the mixed strategy Nash equilibrium, whether the collaborative equilibrium has a focal point solution, and whether introducing a burning money mechanism changes 
the players' behavior towards more collaboration. The games used in the experiment are the hawk-dove game (Part I), the stag hunt game (Part II), and the hawk-dove and stag hunt games with burning money (Part III). This paper sets out very interesting results for Game Theory, one of which is that players do not seem to play according to the mixed Nash equilibrium.

Kotaro Kawamata and Masahide Horita applied game theory to match strategies to international climate change negotiations, by analyzing mechanisms for reducing $\mathrm{CO}^{2}$ and other emissions. The emphasis is on matching models and their equilibrium states in the context of greenhouse gas (GHG) and also combining them to better support the negotiation process.

The following three papers represent advances in Negotiation Support Systems (NSS). In the first paper, Nicola Bellantuono, Donatella Ettorre, Gregory E Kersten and Pierpaolo Pontrandolfo identified guidelines for companies that need to select or design systems to support the procurement of logistics services, thus investigating the link between the design parameters of the e-procurement system and the performance of the attendant process. They considered multi-attribute auction and negotiation mechanisms and adopted the same business case and technological platform to compare them. To do so, they developed controlled lab experiments in order to validate 14 hypotheses, focusing on two key dimensions: (i) the exchange mechanism that rules the transaction and (ii) the problem complexity, which has been operationalized in terms of the number of attributes that describe the sought-after logistics service. The process performance is analyzed in terms of provider's profit, balance, trust, perceived opportunism, satisfaction with substantive outcome, satisfaction with dealing, and satisfaction with relationship.

Tomasz Szapiro and Przemysław Szufel proposed a system able to simulate negotiation among several stakeholders in case of asymmetry of information. The system works as a facilitator and several modes of meditation are envisaged. The model consists of recommendation crowding, lone wolf aggregation and a benchmark evaluation for real negotiation. This paper shows an interesting method for finding outcomes of negotiation with multiple parties using their behavior agent simulation.

Jakub Brzostowski and Tomasz Wachowicz propose a software solution designed for supporting bilateral negotiations of different types and contexts; a NSS called NegoManage. This system also incorporates a profiling mechanism using a linguistic utility scale and a post-negotiation optimization algorithm. It has three distinct aims, namely: (i) to formulate the negotiation problem, i.e. to define the negotiation space and build a scoring system to assess alternatives; (ii) to profile negotiators, i.e. to evaluate their negotiation style; and (iii) to improve the compromise that emerges from the negotiation phase, so as to achieve Pareto efficiency.

The remaining three papers of the special issue present empirical results of group decision and negotiation about emotion and interaction effects; conflict negotiation and resolution on family dispute; and trust aspects for collaboration and negotiation systems.

Bilyana Martinovski discusses if and how activity and interaction affect group decision and negotiation processes by exploring how speakers enter each other's reference frames. She observed authentic data to analyze the problem which she reframes as a 
process affected by interactivity and led by discursive mechanisms such as reciprocal adaptation, which can realize as interactive alignment or/and complex processing.

Naomi Augar and John Zeleznikow developed online support and counseling to enhance family dispute resolution to assist parents who have separated to better handle conflict about determining the future care of their children. In their paper, they described a case study of an organization named Relationships Australia Victoria (RAV), in order to provide insight into how support and counseling organizations in Australia are providing services to clients about family breakdowns.

Xusen Cheng and Linda Macaulay studied the importance of trust in group collaboration, exploring individual trust factors and their development in a computer mediated, collaborative group using group support system tools. They conducted the research using a face to face and a computer mediated collaboration case study and validated previous research factors as risk, benefits, utility value, interest, effort, power, and also found six more factors and validated them: motivation, reliability, reputation, cooperation, task achieving and friendship.

The remaining two papers are included in the next regular issue. Steven Way and Yufei Yuan deal with a vital problem of emergency response, such as an earthquake, a tsunami or a nuclear power plant meltdown. They built a comprehensive system to support the coordination of the many different parties involved in managing an emergency situation of various types and contexts by developing a general framework incorporating context-awareness, multi-parties relationship management and task-based coordination components. This kind of system allows prompt reaction to and the efficient management of the actions required for taking control over the negative effects of any emergency situation. Mireille Ducassé and Peggy Cellier presented a logical multicriteria sort process, based on Logical Information Systems (LIS), in order to allow a fair and fast convergence on islands of agreement, without require a complete and consistent a priori set of preferences. This process logically sort alternatives into categories according to multiple criteria, with the help of a software tool. This paper presents the application of this proposed process on the debriefing of an academic year validation committee.

The papers of this special issue collectively highlight an overview of the standing GDN 2012 conference, based on various conceptual foundations, and also what needs to be done to make the methods and systems useful for Organizations. We hope these papers inspire future researchers in the GDN field.

Acknowledgments We thank the authors for their contributions to this special issue and the cooperation and assistance of many reviewers, whose feedback was very useful in improving the quality of papers submitted. Finally, we would like to express our gratitude to Melvin Shakun, for inviting and supporting us to bring this special issue to completion, with his inspirational leadership for keeping GDN community connected.

\section{References}

Alencar LH, Almeida AT (2010) A model for selecting project team members using multicriteria group decision making. Pesquisa Operacional 30:221-236

Alencar LH, Almeida AT, Morais DC (2010) A multicriteria group decision model aggregating the preferences of decision-makers based on ELECTRE methods. Pesquisa Operacional 30:687-702 
Alfaro C, Gomez J, Lavin JM, Molero JJ (2010) A configurable architecture for e-participatory budgeting support. JeDEM 2(1):39-45

Almeida AT, Costa APCS (2012) Research developments of group decision and negotiation in Latin America. Group Decis Negot 21:129-132

Baccarin E, Madeira ERM, Medeiros CB, Van der Aalst WMP (2011) SPICA'S multi-party negotiation protocol: implementation using YAWL. Int J Cooper Inf Syst 20(3):221-259

Daher SFD, Almeida AT (2012) The use of ranking veto concept to mitigate the compensatory effects of additive aggregation in group decisions on a water utility automation investment. Group Decis Negot 21:185-204

Ekel PI, Queiroz J, Parreiras RO, Palhares RM (2009) Fuzzy set based models and methods of multicriteria group decision making. Nonlinear Anal 71:e409-e419

Krohling RA, Campanharo VC (2011) Fuzzy TOPSIS for group decision making: a case study for accidents with oil spill in the sea. Expert Syst Appl 38(4):4190-4197

Morais DC, Almeida AT (2006) Water supply system decision-making using multicriteria analysis. Water SA 32(2):229-235

Morais DC, Almeida AT (2010) Water network rehabilitation: a group decision-making approach. Water SA 36:487-494

Morais DC, Almeida AT (2012) Group decision making on water resources based on analysis of individual rankings. Omega 40:42-45

Parreiras RO, Ekel PI, Morais DC (2012) Fuzzy set based consensus schemes for multicriteria group decision making applied to strategic planning. Group Decis Negot 21:153-183

Parreiras RO, Ekel P, Martini JSC, Palhares RM (2010) A flexible consensus scheme for multicriteria group decision making under linguistic assessments. Inf Sci 180:1075-1089

Santos BS (1998) Participatory budgeting in Porto Alegre: toward a redistributive democracy. Politics Soc 26(4):461-510

Silva VBS, Morais DC, Almeida AT (2010) A multicriteria group decision model to support watershed committees in Brazil. Water Resour Manag 24:4075-4091 